\title{
Ketidaksesuaian Dosis dan Interval Pemberian Antibiotik pada Lansia di Bangsal Penyakit Dalam RSUD dr Moewardi Solo serta Gambaran Timbulnya Efek Samping yang Merugikan
}

\section{Incompatibility of Dosage and Interval Antibiotic Administration in Elderly in Internal Disease Ward of RSUD dr. Moewardi Solo and Description of The Emergence of Adverse Side Effects}

\author{
Rita Septiana, Risma Sakti Pambudi \\ Program Studi Farmasi, Universitas Sahid Surakarta, Indonesia \\ Email : ritaseptiana0@gmail.com
}

(Diterima : 2019-08-29, disetujui : 2019-11-27)

\begin{abstract}
ABSTRAK
Pertambahan usia menyebabkan penurunan kecepatan aliran darah ginjal dan nilai klirens yang berkaitan dengan fungsi filtrasi ginjal. Penurunan fungsi filtrasi ginjal berdampak pada turunnya kemampuan eliminasi obat sehingga obat dan metabolitnya cenderung terakumulasi dalam darah. Dosis pemberian antibiotik tertentu harus disesuaikan dengan fungsi ginjal pasien. Penelitian ini bertujuan mengetahui persentase ketidaksesuaian dosis dan interval pemberian antibiotik dengan nilai $\mathrm{CrCl}$ pasien lansia serta melihat gambaran efek samping yang timbul dari pemberian antibiotik.

Penelitian ini bersifat obsevasional dengan pengambilan data dari rekam medik secara retrospektif. Sampel penelitan adalah 133 pasien lansia rawat inap di bangsal penyakit dalam RSUD dr Moewardi Solo periode Januari sampai Mei 2019 berusia usia $\geq 60$ tahun dengan diagnosis Pneumonia atau Infeksi Saluran Kemih (ISK) atau Selulitis atau sepsis dengan data rekam medis yang lengkap. Antibiotik yang dievaluasi adalah seluruh antibiotik yang diberikan pada pasien saat dirawat.

Hasil penelitian menunjukkan dari 133 pasien ditemukan 191 kasus pemberian antibiotik. Ketidaksesuaian dosis dan interval pemberian antibiotik dengan nilai $\mathrm{CrCl}$ pasien adalah sebesar $36,65 \%$ (70 kasus). Kejadian efek samping yang timbul karena pemberian antibiotik adalah mual dan muntah (10 pasien) dan diare (4 pasien).
\end{abstract}

Kata kunci : antibiotik, $\mathrm{CrCl}$, kesesuaian dosis, lansia

\section{ABSTRACT}

Age increases causes a decrease in renal blood flow velocity and clearance values related to renal filtration function. A decrease in kidney filtration function results in a decrease in the ability of drug elimination so that the drug and its metabolites tend to accumulate in the blood. The dose of certain antibiotics must be adjusted to the patient's kidney function. This study aims to determine the percentage mismatch of dose and the interval of antibiotic administration with the $\mathrm{CrCl}$ value of elderly patients and to see a picture of the side effects arising from the administration of antibiotics.

This research was observational with data retrospective retrieval of medical records. The research sample of 133 elderly patients hospitalized in the ward of the RSUD dr. Moewardi Solo period January to May 2019 aged $\geq 60$ years with a diagnosis of pneumonia, Urinary Tract Infections (UTI), cellulitis and sepsis with complete medical record data. The antibiotics evaluated are all antibiotics given to the patient while being treated.

The results showed that of 133 patients found 191 cases of antibiotic administration. Mismatch of dosage and interval of antibiotic administration with the patient's $\mathrm{CrCl}$ value was $36,65 \%$ ( 70 cases). The incidence of side effects arising from antibiotic administration was nausea and vomiting (10 patients) and diarrhea (4 patients).

Keywords: Antibiotics, CrCl, Dose Conformity, Elderly 


\section{PENDAHULUAN}

Di negara-negara berkembang, termasuk di Indonesia pertumbuhan penduduk lansia (lanjut usia) diprediksi akan meningkat dengan cepat dimasa yang akan datang (Kemenkes RI, 2013). Lansia berdasarkan Undang-Undang Republik Indonesia Nomor 13 Tahun 1998 tentang Kesejahteraan Lanjut Usia adalah seseorang yang telah mencapai usia 60 tahun ke atas (UU RI, 1998). Kelompok lansia memiliki karakteristik khusus antara lain rentan mengalami penyakit kronis, mengalami penurunan fungsi organ dan penurunan status fungsional (Darmojo, B., 2011).

Adanya proses penuaan berdampak pada penurunan fungsi beberapa organ tubuh, salah satunya adalah ginjal. Nilai klirens yang berkaitan dengan fungsi filtrasi ginjal dan kecepatan aliran darah ginjal menurun seiring pertambahan usia (Ritschel, W.A. dan Kearns, G.L., 2004). Penurunan fungsi filtrasi ginjal berdampak pada turunnya kemampuan eliminasi obat sehingga obat dan metabolitnya cenderung terakumulasi dalam darah. Hal tersebut menyebabkan kadar obat dalam darah meningkat melebihi rentang dosis terapi dan dapat menimbulkan efek toksik yang tidak diinginkan (Shargel dkk., 2005).

Penurunan fungsi fisiologi tubuh pada lansia menyebabkan munculnya berbagai penyakit degeneratif yang bersifat kronis. Penyakit degeneratif berdampak pada turunnya daya tahan tubuh seseorang sehingga kelompok umur lansia rentan terkena infeksi (Kemenkes RI, 2013). Antibiotik merupakan obat yang diberikan untuk menghambat pertumbuhan atau membasmi bakteri penyebab infeksi (Setiabudy, R., 2007). Antibiotik merupakan salah satu jenis obat yang sering diresepkan untuk pasien, berdasarkan penelitian yang dilakukan di RSUD Dr. Soetomo dan RSUD dr. Kariadi sebanyak $84 \%$ pasien di rumah sakit mendapatkan resep antibiotik (Kemenkes RI, 2011).

Dosis pemberian antibiotik tertentu yang eliminasi utamanya melalui urin harus disesuaikan dengan fungsi filtrasi ginjal pasien. Perkiraan klinis fungsi filtrasi ginjal dinyatakan dalam bersihan kreatinin (Creatinine Clearance $=\mathrm{CrCl}$ ) (Kemenkes RI, 2011; APhA's, 2015). Penelitian di kanada menunjukkan sebanyak $64 \%$ pasien lansia rawat jalan menerima antibiotik dengan dosis yang tidak sesuai dengan nilai CrClnya (Faraq dkk., 2014). Ketidaksesuaian dosis pemberian obat dapat menyebabkan peningkatan angka morbiditas termasuk akibat timbulnya efek samping (Fahimi dkk., 2012).

Berdasarkan pertimbangan perlunya penyesuaian dosis obat pada pasien lansia, maka dilakukan penelitian dengan judul Ketidaksesuaian Dosis dan Interval Pemberian Antibiotik pada Lansia serta Gambaran Timbulnya Efek Samping yang Merugikan.

\section{METODE PENELITIAN}

\section{Rancangan Penelitian}

Penelitian

tentang ketidaksesuaian dosis dan interval pemberian antibiotik pada pasien lansia merupakan penelitian non eksperimental (observasional). Pengumpulan data pasien dilakukan secara retrospektif melalui penelusuran data rekam medis. 
Subjek penelitian yaitu pasien lansia rawat inap di bangsal penyakit dalam RSUD dr Moewardi Solo periode Januari sampai Mei 2019 yang memenuhi kriteria inklusi. Kriteria inklusi penelitian ini adalah Pasien rawat inap usia $\geq 60$ tahun dengan diagnosis Pneumonia, Infeksi Saluran Kemih (ISK), Selulitis dan sepsis dengan data rekam medis yang lengkap. Jumlah sampel yang memenuhi kriteria inklusi penelitian adalah 133 pasien dengan 191 kasus pemberian antibiotik. Antibiotik yang dievaluasi adalah seluruh antibiotik yang diberikan pada pasien saat dirawat.

\section{Instrumen Penelitian}

Alat dan bahan yang digunakan dalam penelitian ini adalah rekam medik sebagai sumber informasi tentang pasien, lembar pengumpulan data, alat tulis, alat hitung dan Drug Information Handbook (DIH) 24 $4^{\text {th }}$ edition digunakan sebagai salah satu literatur untuk menentukan kesesuaian dosis dan interval pemberian antibiotik pada pasien.

\section{Jalannya Penelitian}

Penelitian ini dilakukan dalam beberapa tahap. Tahap pertama adalah tahap persiapan dimulai dengan studi pustaka dan perijinan terkait penelitian. Tahap kedua adalah tahap pengambilan data. Tahap ketiga adalah tahap pengolahan data penelitian yang meliputi penghitungan nilai $\mathrm{CrCl}$ seluruh pasien, penilaian kesesuaian dosis dan interval pemberian regimen antibiotik serta analisis efek samping yang sering ditemukan. $\mathrm{CrCl}$ pasien dihitung menggunakan persamaan CockroufGault. Tahap terakhir adalah tahap pengambilan kesimpulan.

\section{HASIL DAN PEMBAHASAN \\ 1. Karakteristik Umum Pasien}

Karakteristik umum pasien dalam penelitian ini meliputi jenis kelamin, usia, status penurunan fungsi ginjal dan jenis infeksinya. Informasi tentang karakteristik umum pasien tersaji dalam tabel 1.

Berdasarkan karakteristik jenis kelamin, pasien terdiri dari 65 pasien laki-laki dan 68 pasien perempuan. Berdasarkan karakteristik usia, pasien lansia dikelompokkan menjadi lanjut usia (elderly) antara usia 60 sampai 74 tahun dan lanjut usia tua (old) antara usia 75 sampai 90 tahun (WHO, 2015). Sebanyak $74,44 \%$ pasien berada dalam usia elderly. Usia terendah pasien dalam penelitian ini adalah 60 tahun dan usia tertinggi 88 tahun.

Berdasarkan karakteristik fungsi ginjal, 75 pasien lansia (56,39 \%) dalam penelitian ini memiliki status penurunan fungsi ginjal sedang. Status fungsi filtrasi ginjal pasien dinilai berdasarkan pedoman dari organisasi ginjal dunia KDOQI Guidelines, penurunan fungsi filtrasi ginjal dikategorikan menjadi : tidak ada penurunan fungsi ginjal yaitu untuk seseorang dengan nilai $\mathrm{CrCl} \geq 90$ $\mathrm{ml} /$ menit, penurunan fungsi ginjal ringan untuk seseorang dengan nilai $\mathrm{CrCl}$ antara 60-89,9 $\mathrm{ml} /$ menit, penurunan fungsi ginjal sedang untuk seseorang dengan nilai $\mathrm{CrCl} 30-59,9 \mathrm{ml} /$ menit, penurunan fungsi ginjal berat untuk seseorang dengan nilai $\mathrm{CrCl}$ 15-29,9 $\mathrm{ml} /$ menit dan kategori End stage renal disease (ESRD) untuk seseorang dengan nilai $\mathrm{CrCl}<15 \mathrm{ml} /$ menit) (KDOQI, 2002).

Berdasarkan karakteristik jenis infeksi yang diderita pasien terdiri dari 
ISK $(35,34 \%)$, pneumonia $(34,59 \%)$, sepsis $(16,54 \%)$ dan selulitis (13,53 \%). Usia lanjut merupakan salah satu faktor resiko dari pneumonia (Depkes RI, 2005), sehingga dengan semakin bertambahnya usia akan meningkat pula resiko kejadian pneumonia. Beberapa masalah kesehatan menyebabkan lansia lebih banyak terbaring di tempat tidur, penggunaan NGT dan kateter membuat lansia rentan terkena infeksi (Ozdemir dan Dizbay, 2015). Prevalensi ISK pada pasien yang memakai kateter adalah $70-80 \%$ dan $10-30 \%$ pasien tersebut akan mengalami bakteriuria (Magill dkk., 2014). Penyebab sepsis pada lansia adalah karena adanya penyakit penyerta, menjalani rawat inap berkepanjangan, penurunan kekebalan tubuh dan keterbatasan fungsional (Nasa dkk., 2012). Setiap jenis infeksi dalam tubuh seperti infeksi kulit, pneumonia, ISK atau bagian lain dari tubuh dapat menyebabkan sepsis termasuk (CDC, 2015). Secara umum pneumonia, sepsis, ISK dan selulitis merupakan jenis infeksi yang sering ditemukan pada pasien lansia rawat inap.

2. Gambaran Umum Pemberian Antibiotik pada Lansia

Antibiotik yang dievaluasi dalam penelitian ini adalah seluruh antibiotik yang diberikan pada saat pasien dirawat.

Tabel 1. Karakteristik Umum Pasien Lansia di Bangsal Penyakit Dalam RSUD dr Moewardi Solo periode Januari - Mei 2019

\begin{tabular}{lcc}
\hline \multicolumn{1}{c}{ Karakteristik } & $\begin{array}{c}\text { Jumlah } \\
\text { Pasien } \\
(\mathbf{n = 1 3 3 )}\end{array}$ & $\begin{array}{c}\text { Persentase } \\
\text { (\%) }\end{array}$ \\
\hline $\begin{array}{l}\text { Jenis Kelamin } \\
\text { Laki-laki }\end{array}$ & 65 & 48,87 \\
Perempuan & 68 & 51,13 \\
Usia (tahun) & & \\
60-74 & 99 & 74,44 \\
75-90 & 34 & 25,56 \\
Status Fungsi Filtrasi Ginjal & & \\
Ringan & 26 & 19,55 \\
Sedang & 75 & 56,39 \\
Berat & 27 & 20,30 \\
ESRD & 5 & 3,76 \\
Jenis infeksi & & \\
ISK & 47 & 35,34 \\
Pneumonia & 46 & 34,59 \\
Sepsis & 22 & 16,54 \\
Selulitis & 18 & 13,53 \\
\hline
\end{tabular}


Dari 133 pasien yang memenuhi kriteria inklusi ditemukan 191 kasus penggunaan antibiotik, hal ini dikarenakan beberapa pasien mendapatkan lebih dari satu kali resep antibiotik.

Jenis antibiotik yang paling sering diberikan pada pasien adalah ampisilinsulbaktam (54,45\% kasus). Antibiotik ini diberikan untuk pasien dengan diagnosa pneumonia (37 kasus), ISK (34 kasus), sepsis (18 kasus) dan selulitis (15 kasus). Informasi tentang pemberian antibiotik pasien lansia tersaji dalam tabel 2.

Ampisilin-sulbaktam merupakan antibiotik golongan penisilin yang diberikan bersamaan dengan penghambat betalaktam. Ampisilin termasuk dalam antibiotik extended spectrum yaitu antibiotik yang efektif terhadap bakteri Gram positif, namun juga aktif terhadap beberapa bakteri Gram negatif. Ampisilin-sulbaktam dapat diberikan untuk intrabdominal infections, skin and skin structure infections, orbital cellulitis, pneumonia dan urinary tract infections (APhA's, 2015; ATS/IDS, 2007; ATS, 2005; Setiabudy, R., 2007).

3. Gambaran Ketidaksesuaian Dosis dan Intreval Pemberian Antibiotik

Penilaian kesesuaian dosis dan interval pemberian antibiotik dilihat berdasarkan nilai $\mathrm{CrCl}$ masing-masing pasien.

Tabel 2. Gambaran Pemberian Antibiotik Pasien Lansia di Bangsal Penyakit Dalam RSUD dr Moewardi Solo periode Januari - Mei 2019

\begin{tabular}{lcc}
\hline Jenis Antibiotik & $\begin{array}{c}\text { Jumlah Kasus } \\
(\mathbf{n = 1 9 1 )}\end{array}$ & $\begin{array}{c}\text { Persentase } \\
(\%)\end{array}$ \\
\hline Ampisilin-sulbactam & 104 & 54,45 \\
Levofloksasin & 24 & 12,57 \\
\hline Ampisilin & 16 & 8,38 \\
Ciprofloksasin & 13 & 6,81 \\
\hline Gentamisin & 9 & 4,1 \\
\hline Azitromisin & 5 & 2,62 \\
Clindamisin & 5 & 2,62 \\
Metronidazole & 4 & 2,09 \\
\hline Cefiksim & 3 & 1,57 \\
Amikasin & 2 & 1,05 \\
\hline vancomisin & 2 & 1,05 \\
Cotrimoksazol & 1 & 0,52 \\
\hline Eritromisin & 1 & 0,52 \\
Cetriakson & 1 & 0,52 \\
\hline Meropenem & 1 & 0,52 \\
\hline
\end{tabular}


Hasil penelitian menunjukkan, dari 191 kasus pemberian antibiotik, sebanyak $63,35 \%$ (104 kasus) sudah sesuai dengan $\mathrm{CrCl}$ pasien baik dosis maupun intervalnya. Angka kesesuaian tersebut lebih besar dibandingkan hasil penelitian sebelumnya yang dilakukan oleh Faraq dkk. (2014) dimana kesesuaian dosis pemberian antibiotik pada pasien lansia di poli rawat jalan adalah $36 \%$. Penelitian lain menunjukkan kesesuaian dosis pemberian antibiotik pada pasien rawat inap dengan gangguan fungsi ginjal adalah sebesar $43,7 \%$ (Fahimi dkk., 2012).

Dalam penelitian ini ditemukan $36,65 \%$ (70 kasus) ketidaksesuaian pemberian antibiotik. Adapun jenis ketidaksesuaian pemberian antibiotik tersebut meliputi : ketidaksesuaian dosis pemberian (9 kasus), ketidaksesuaian interval pemberian (54 kasus) serta ketidaksesuaian dosis dan interval pemberian ( 7 kasus). Jenis ketidaksesuaian pemberian antibiotik dalam penelitian ini tersaji dalam tabel 3 .

Ketidaksesuaian interval pemberian antibiotik merupakan kasus yang paling banyak ditemui. Salah satu kasus pemberian antibiotik dengan interval yang tidak sesuai adalah pada pasien dengan diagnosis sepsis, dengan nilai $\mathrm{CrCl} 34,12 \mathrm{ml} /$ menit dan mendapatkan terapi gentamisin $80 \mathrm{mg}$ setiap 12 jam. Dosis pemberian gentamisin menurut literatur adalah 3 sampai $5 \mathrm{mg} / \mathrm{kgBB} /$ hari diberikan dalam dosis terbagi setiap 8 jam atau 1-1,7 $\mathrm{mg} / \mathrm{kgBB}$ setiap 8 jam. Berat badan pasien tersebut adalah $68 \mathrm{~kg}$ sehingga dosis pemberiannya antara 68 sampai $115,6 \mathrm{mg}$ setiap 8 jam. Berdasarkan literatur, untuk pasien dengan $\mathrm{CrCl} 20$ $40 \mathrm{ml} /$ menit gentamisin diberikan dengan dosis tetap (sesuai indikasi) dengan interval pemberian setiap 24 jam (APhA's, 2015). Berdasarkan literatur dosis penyesuaian gentamisin untuk pasien tersebut adalah 68 - 115,6 mg setiap 24 jam. Dosis pemeberian pada pasien tersebut sudah tepat namun intervalnya pemberianya tidak tepat.

Kasus ketidaksesuaian dosis pemberian antibiotik salah satunya pada pasien dengan diagnosis ISK yang mendapat terapi dengan levofloksasin 750 mg setiap 24 jam, nilai $\mathrm{CrCl}$ pasien tersebut adalah 29,06 $\mathrm{ml} /$ menit. Berdasarkan literatur, dosis pemberian levofloksasin untuk sedangkan dosis penyesuaian untuk pasien dengan nilai $\mathrm{CrCl} \quad 20-49 \mathrm{ml} /$ menit dosis awal pemberian levofloksasin adalah 250$500 \mathrm{mg}$, selanjutnya $250 \mathrm{mg}$ setiap 2448 jam (APhA's, 2015). Pemberian obat dengan dosis yang lebih besar menyebabkan kadar puncak obat dalam darah pasien tersebut berada dalam kadar toksik karena melebihi rentang kadar terapik (Kazouini dkk., 2011).

Kasus ketidaksesuaian dosis dan interval pemberian antibiotik salah satunya adalah pemberian cefiksim tab 200 mg setiap 12 jam pada pasien dengan nilai $\mathrm{CrCl} 49,19 \mathrm{ml} / \mathrm{menit}$, pasien tersebut didiagnosa ISK. Dosis lazim pemberian cefiksim adalah $400 \mathrm{mg}$ perhari, dalam dosis terbagi setiap 1224 jam. Berdasarkan pustaka, dosis penyesuaian untuk pasien dengan nilai $\mathrm{CrCl} 21-59 \mathrm{ml} /$ menit adalah $260 \mathrm{mg}$ setiap 24 jam. Dosis dan interval pemberian pada pasien tersebut tidak sesuai dengan nilai $\mathrm{CrCl}$ pasien, 
sehingga jumlah obat yang masuk dalam tubuh pasien (400 $\mathrm{mg}$ perhari) lebih besar dari yang rekomendasikan literatur (260 mg perhari).

Tabel 3. Jenis Ketidaksesuaian Pemberian Antibiotik pada Pasien Lansia

\begin{tabular}{|c|c|c|c|c|}
\hline $\begin{array}{c}\text { Jenis } \\
\text { Antibiotik }\end{array}$ & $\begin{array}{l}\text { Jumlah } \\
(\mathrm{n}=70)\end{array}$ & $\begin{array}{l}\text { Dosis pada } \\
\text { Pasien }\end{array}$ & Dosis Menurut Literatur & Ket. \\
\hline \multirow{5}{*}{$\begin{array}{l}\text { Ampisillin- } \\
\text { Sulbactam }\end{array}$} & 16 & $1,5 \mathrm{~g} / 8$ jam & $1,5-3 \mathrm{~g} / 12 \mathrm{jam}$ & $i$ \\
\hline & 7 & $1,5 \mathrm{~g} / 6$ jam & $1,5-3 \mathrm{~g} / 12$ jam & $i$ \\
\hline & 2 & $1,5 \mathrm{~g} / 6 \mathrm{jam}$ & $1,5-3 \mathrm{~g} / 24$ jam & $i$ \\
\hline & 3 & $1,5 \mathrm{~g} / 12$ jam & 1,5 - $3 \mathrm{~g} / 6$ jam & $i$ \\
\hline & 1 & $1,5 \mathrm{~g} / 24$ jam & $1,5-3 \mathrm{~g} / 12 \mathrm{jam}$ & $i$ \\
\hline \multirow{5}{*}{$\begin{array}{l}\text { Levo- } \\
\text { floksasin }\end{array}$} & 8 & 750 mg / 24 jam & $\begin{array}{l}\text { dosis awal } 250-500 \mathrm{mg}, \\
\text { selanjutnya } 250 \mathrm{mg} / 24-48 \text { jam }\end{array}$ & $d$ \\
\hline & 1 & 750 mg / 48 jam & $\begin{array}{l}\text { dosis awal } 250 \text { - } 500 \text { mg, } \\
\text { selanjutnya } 250 \mathrm{mg} / 24 \text { - } 48 \text { jam }\end{array}$ & $d$ \\
\hline & 1 & $500 \mathrm{mg} / 12 \mathrm{jam}$ & $\begin{array}{l}\text { dosis awal } 250 \text { - } 500 \mathrm{mg} \text {, } \\
\text { selanjutnya } 250 \mathrm{mg} / 24 \text { - } 48 \text { jam }\end{array}$ & $i$ \\
\hline & 1 & 750 mg / 12 jam & 250 - 750 mg / 24 jam & $i$ \\
\hline & 1 & 500 mg / 12 jam & 250 - 750 mg / 24 jam & $i$ \\
\hline \multirow{4}{*}{ Ampisillin } & 3 & $1 \mathrm{~g} / 8 \mathrm{jam}$ & $1-2 \mathrm{~g} / 6 \mathrm{jam}$ & $i$ \\
\hline & 1 & $1,5 \mathrm{~g} / 8 \mathrm{jam}$ & $1-2 \mathrm{~g} / 4-6 \mathrm{jam}$ & $i$ \\
\hline & 1 & $1 \mathrm{~g} / 24$ jam & $1-2 \mathrm{~g} / 6-12 \mathrm{jam}$ & $i$ \\
\hline & 1 & $1,5 \mathrm{~g} / 12 \mathrm{jam}$ & $1-2 \mathrm{~g} / 6 \mathrm{jam}$ & $i$ \\
\hline \multirow{6}{*}{ Gentamisin } & 1 & $80 \mathrm{mg} / 12$ jam & 68 - 113,4 mg / 24 jam & $i$ \\
\hline & 1 & 80 mg / 12 jam & 55 - 91,7 mg / 24 jam & $i$ \\
\hline & 1 & 160 mg / 24 jam & 55 - 93,5 / 8 jam & $d, i$ \\
\hline & 1 & 320 mg / 24 jam & $50-85$ mg / 12 jam & $d, i$ \\
\hline & 1 & $1 \mathrm{~g} / 12 \mathrm{jam}$ & $48-80$ mg / 24 jam & $d, i$ \\
\hline & 1 & 50 mg / 12 jam & $68-113,4$ mg / 24 jam & $d, i$ \\
\hline \multirow{3}{*}{ Azitromisin } & 1 & 500 mg / 8 jam & $250-600 \mathrm{mg} / 24$ jam & $i$ \\
\hline & 1 & 500 mg / 12 jam & $250-600$ mg / 24 jam & $i$ \\
\hline & 1 & 250 mg / 12 jam & $250-600 \mathrm{mg} / 24 \mathrm{jam}$ & $i$ \\
\hline Cefiksim & 2 & 200 mg / 12 jam & 260 mg / 24 jam & $d, i$ \\
\hline
\end{tabular}




\begin{tabular}{cllll}
\hline & 1 & $100 \mathrm{mg} / 12 \mathrm{jam}$ & $260 \mathrm{mg} / 24 \mathrm{jam}$ & $d, i$ \\
\hline Cipro- & 1 & $200 \mathrm{mg} / 24 \mathrm{jam}$ & $200-400 \mathrm{mg} / 12 \mathrm{jam}$ & $i$ \\
floksasin & 1 & $400 \mathrm{mg} / 12 \mathrm{jam}$ & $200-400 \mathrm{mg} / 18-24 \mathrm{jam}$ & $i$ \\
\hline \multirow{2}{*}{ Metronidazol } & 1 & $500 \mathrm{mg} / 12 \mathrm{jam}$ & $412,5-825 \mathrm{mg} / 6 \mathrm{jam}$ & $i$ \\
& 1 & $500 \mathrm{mg} / 12 \mathrm{jam}$ & $337,5-675 \mathrm{mg} / 6 \mathrm{jam}$ & $i$ \\
& 1 & $500 \mathrm{mg} / 12 \mathrm{jam}$ & $487,5-975 \mathrm{mg} / 6 \mathrm{jam}$ & $i$ \\
\hline Clindamisin & 1 & $1500 \mathrm{mg} / 8 \mathrm{jam}$ & $435-870 \mathrm{mg} / 6 \mathrm{jam}$ & $i$ \\
\hline Meropenem & 1 & $300 \mathrm{mg} / 12 \mathrm{jam}$ & $150-450 \mathrm{mg} / 6-8 \mathrm{jam}$ & $i$ \\
\hline Amikasin & 1 & $1 \mathrm{~g} / 8 \mathrm{jam}$ & $0,5-1 \mathrm{~g} / 12 \mathrm{jam}$ & $i$ \\
\hline Vancomisin & 1 & $1 \mathrm{~g} / 12 \mathrm{jam}$ & $0,75-1,5 \mathrm{~g} / 24 \mathrm{jam}$ & $i$ \\
\hline
\end{tabular}

Keterangan: $i=$ interval tidak sesuai; $d=$ dosis tidak sesuai; $d, i=$ dosis dan interval tidak sesuai

\section{Gambaran Efek Samping yang Timbul dari Penggunaan Antibiotik}

Efek samping yang dimaksud dalam penelitian ini adalah keluhan yang dirasakan pasien setelah mendapatkan antibiotik dan tercatat dalam rekam medik. Keluhan yang merupakan tanda dan gejala dari penyakit yang diderita pasien tidak diamati. Keluhan yang tidak diamati antara lain demam (tanda umum adanya infeksi), batuk, sesak dan nyeri dada (karena pneumonia), nyeri perut dan sakit saat berkemih (karena ISK) serta nyeri kaki (karena selulitis) (CDC, 2015).

Keluhan yang dicurigai karena efek samping penggunaan antibiotik adalah mual dan muntah (10 pasien) dan diare (4 pasien). Meskipun kemungkinan kejadiannya relatif kecil (< $10 \%$ ), sebagian besar antibiotik memiliki efek samping berupa mual, muntah dan diare (APhA's, 2015; ATS/IDS, 2007; ATS, 2005).

Kondisi seperti mual dan muntah dapat menyebabkan penurunan nafsu makan pasien dan secara tidak langsung akan mempengaruhi status gizi pasien. Diare menyebabkan keluarnya cairan secara berlebihan dari dalam tubuh, hal ini perlu diwaspadai karena dapat menyebabkan dehidrasi. Dehidrasi yang tidak tertangani akan menyebabkan keluarnya mineral dari dalam tubuh seseorang selain itu juga akan membayakan pasien tersebut.

Kejadian efek samping yang dialami pasien tergolong ringan, namun harus tetap ditangani dan dimonitoring. Penurunan nafsu makan dan diare dapat menyebbakan tidak terpenuhinya kebutuhan nutrisi pasien. Memenuhi kebutuhan nutrisi lansia sangat penting untuk pemeliharaan kesehatan, pemeliharaan fungsional tubuh, dan 
kualitas hidup seseorang (Leslie, W. dan Hankey, C., 2015).

\section{KESIMPULAN}

1. Ketidaksesuaian dosis dan interval pemberian antibiotik dengan nilai $\mathrm{CrCl}$ pasien lansia rawat inap di bangsal penyakit dalam RSUD $d r$ Moewardi Solo periode Januari-Mei 2019 adalah $36,65 \%$,

2. Kejadian efek samping yang timbul karena pemberian antibiotik adalah mual dan muntah (10 pasien) dan diare (4 pasien)

\section{DAFTAR PUSTAKA}

APhA's, 2015. Drug Information Handbook, 24th ed. Lexicomp, U.S.

ATS, 2005. Guidelines for the Management of Adults with Hospital-acquired, Ventilatorassociated, and Healthcareassociated Pneumonia.

ATS/IDS, 2007. Infectious Diseases Society of America/American Thoracic Society Consensus Guidelines on the Management of Community-Acquired Pneumonia in Adults.

CDC, 2015. Sepsis Fact Sheet 'A Potentially Deadly Outcome From An Infection.

Darmojo, B., 2011. Buku Ajar Geriatri (Ilmu Kesehatan Usia Lanjut), 4th ed. Balai Penerbit FKUI, Jakarta.

Depkes RI, 2005. Pharmaceutical Care untuk Penyakit Infeksi Saluran Pernapasan.

Fahimi, F., Emami, S., dan Farokhi, F.R., 2012. The Rate of
Antibiotic Dosage Adjustment in Renal Dysfunction. Iranian Journal of Pharmaceutical Research, 11: 157-161.

Faraq, A., Garg, A., Li, L., dan Jain, A.K., 2014. Dosing Errors in Prescribed Antibiotics for Older Persons with CKD: A Retrospective Time Series Analysis. Elsevier Inc.

KDOQI, 2002. KDOQI Clinical Practice Guidelines for Chronic Kidney Disease: Evaluation, Classification, and Stratification.

Kemenkes RI, 2011. Pedoman Pelayanan Kefarmasian untuk Terapi Antibiotik.

Kemenkes RI, 2013. 'Gambaran Kesehatan Lanjut Usia di Indonesia', Kementrian Kesehatan Republik Indonesia.

Kazouini, A., Mohammed, B.S., Simpson, C.R., Helms, P.J., dan McLay, J.S., 2011. Paracetamol prescribing in primary care: too little and too much?: Paracetamol prescribing in primary care. British Journal of Clinical Pharmacology, 72: 500504.

Leslie, W. dan Hankey, C., 2015, Aging, Nutrisional Status and Healt. Journal Healthcare, 3 : 648-658.

Magill, S.S., Edwards, J.R., Bamberg, W., Beldavs, Z.G., Dumyati, G., Kainer, M.A., dkk., 2014. Multistate Point-Prevalence Survey of Health CareAssociated Infections. New England Journal of Medicine, 370: 1198-1208.

Nasa, P., Juneja, D., dan Singh, O., 2012. Severe Sepsis and Septic 
Shock in The Elderly: An

Overview. World Journal of

Critical Care Medicine, 1: 23-30.

Ozdemir, K. dan Dizbay, M., 2015.

Nosocomial Infection and Risk

Factors in Elderly Patients in Intensive Care Units. Journal of Microbiology and Infectious Diseases, 5: 38-43.

Ritschel, W.A. dan Kearns, G.L., 2004. Handbook of Basic Pharmacokinetics, 4th ed. Intelligence Publication, Hamilton.

Setiabudy, R., 2007. Antimikroba, dalam: Bagian Farmakologi Universitas Indonesia, Farmakologi Dan Terapi. Balai Penerbit FKUI, Jakarta, hal. 585-598.

Shargel, L., Wu-Pong, S., dan Yu, A.B.., 2005. Applied Biopharmaceutics and Pharmacokinetics, 5th ed. McGaw-Hill, New York.

UU RI, 1998. Undang-undang Republik Indonesia Nomor 13 Tahun 1998 tentang Kesejahteraan Lanjut Usia.

WHO, 2015. Health Statistics and Information System: Definition of an Older or Elderly Person. 